\title{
Que professor teremos na educação brasileira: nativo, imigrante ou e-migrante digital?
}

\author{
Ricardo M. Nicolau ${ }^{1}$, Gustavo P. Pessoa ${ }^{2}$, Fernanda J. Costa ${ }^{3}$ \\ ${ }^{1}$ Departamento de Engenharia de Computação - Fundação Presidente Antônio Carlos - \\ Campus Conselheiro Lafaiete - 36.400-000 - Conselheiro Lafaiete - MG - Brasil \\ ${ }^{2}$ Departamento de Ciências da Natureza - Instituto Federal de Minas Gerais - Campus \\ Congonhas - 36.415-000-MG - Brasil \\ ${ }^{3}$ Departamento de Ciências Biológicas - Universidade do Estado de Minas Gerais \\ 32.415-250 - Ibirité - MG - Brasil \\ ricnic.br@gmail.com, gustavo.pessoa@ifmg.edu, fernanda.costa@uemg.br
}

\begin{abstract}
Digital information and communication technologies (TDIC) have been present for some time in our lives, however, in schools this "revolution" has not happened. One of the explanations for this phenomenon was the lack of ability of the teachers in the handling of the TDIC. The aim of this work, based on the results of a qualitative-quantitative research done between the years of 2015 and 2017, is to discuss why the TDICs are little incorporated in the classroom with educational purposes, even with the arrival of the native digital teachers. What has been noticed is that the school culture is still a great obstacle to the incorporation of TDIC in school. The present moment requires a qualification that doesn't result in e-migrant subjects.
\end{abstract}

Resumo. As tecnologias digitais de informação e comunicação estão presentes há tempos em nossas vidas, porém, nas escolas, esta "revolução" não aconteceu. Uma das explicações deste fenômeno era a falta de habilidade dos professores no manuseio das TDIC. Este trabalho, com base em resultados de pequisa quali-quantitativa realizada entre 2015 e 2017, tem como objetivo discutir porque as TDIC ainda são pouco utilizadas na sala de aula com fins educativos, mesmo com a chegada de docentes nativos digitais. $O$ que se percebeu é que a cultura escolar ainda é um grande entrave à incorporação das TDIC na escola. O momento exige uma formação que não resulte em sujeitos e-migrantes.

\section{Introdução}

Nativos e imigrantes digitais (Prensky, 2001), mito ou realidade? Embora essa classificação ainda seja tema de debates, aceita-se amplamente que em praticamente todas as áreas as tecnologias digitais de informação e comunicação (TDIC) exercem grande influência, alterando formas de realizar processos, como também a velocidade de ocorrência deles (Castells, 1999; Lévy, 2011). Esse processo de transformação vem se intensificando de tal modo que se estabeleceu uma cultura digital, cada dia mais complexa. Quem nasce nos dias atuais, cresce imerso nessa cultura.

$\mathrm{Na}$ medida em que se disseminaram as TDIC, crianças e jovens passaram a fazer uso delas. Contudo, isso se deu muito mais fora do que dentro das escolas. Quando se 
VII Congresso Brasileiro de Informática na Educação (CBIE 2018)

Anais do XXIV Workshop de Informática na Escola (WIE 2018)

compara a lenta apropriação de usos educativos das TDIC em sala de aula e a rápida disseminação delas na sociedade, constata-se que há uma falta de sincronismo entre tecnologia e educação (Marinho, 2006). Fora da escola se reforçaram os contornos dessa cultura digital; no ambiente escolar foi se constituindo uma percepção de que professores e alunos são indivíduos de tempos diferentes. Desde os anos 1980, enquanto os professores enfrentavam dificuldades para incorporá-las à sua prática pedagógica, os alunos eram apontados como aqueles que, por terem nascido na Era Digital, apresentavam maior facilidade para se apropriarem das novidades tecnológicas. Nesse cenário de dificuldades para integração das TDIC ao currículo escolar, no ano de 2001, Marc Prensky, estudando os problemas da educação americana, identificou esse distanciamento entre professores e alunos e cunhou os termos: nativo digital $\boldsymbol{e}$ imigrante digital (Prensky, 2001). Na opinião de Prensky, os nascidos após os anos 1980 por terem crescido imersos na cultura digital, sendo cada vez mais influenciados por ela, devem ser chamados de nativos digitais. E os que nasceram antes, o autor denominou imigrantes digitais, visto que grande parte da formação deles se deu com pouco ou nenhum contato com as TDIC. Caracterizando os imigrantes digitais, o autor argumenta que os nascidos antes dos anos 1980 foram socializados em uma realidade diferente, aprenderam a pensar, resolver seus problemas e enxergar o mundo sem fazerem uso de TDIC. As vivências de uma parcela significativa de suas vidas, e o aprendizado resultante dessas experiências, se deram em uma cultura que não era digital. Por isso, ao procurarem se inserir na nova cultura, adaptando-se às mudanças que as TDIC agora provocam na forma como o ser humano interage com o mundo, esses imigrantes carregam, uns mais, outros menos, um sotaque que revela suas formas de pensar e agir, aprendidas em um outro contexto. Os nativos, por seu turno, define o mesmo autor, são aqueles que nasceram a partir dos anos 1980, cresceram imersos na cultura digital, e por isso manifestam diferentes modos de pensar e agir. Segundo Prensky - e talvez aí esteja um dos aspectos questionáveis desses conceitos - os nativos, por terem nascido na Era Digital, naturalmente teriam maior facilidade para dominar as novas tecnologias, não se ajustando aos velhos paradigmas que caracterizam os processos tradicionais de ensinar e aprender que ainda vigem na escola.

$\mathrm{O}$ autor foi ainda mais longe, sugerindo que os nativos digitais, por terem se desenvolvido nesse novo ambiente, talvez tenham sofrido modificações em sua conformação física. Conquanto pareça ser muito cedo para se estabelecer uma demarcação tão acentuada, outros estudos apontam na mesma direção. É o caso, por exemplo, da pesquisa realizada por Nicolaci-da-Costa (2005) nos primeiros anos do novo milênio. A autora alertou que já se podiam identificar os contornos de uma nova configuração psíquica determinada pela Era Digital. A questão é controversa, até por ser recente, sobretudo quando se investiga causas de modificações na biologia humana. Para alguns pesquisadores, tais como Kirschner e Bruyckere (2017), essa caracterização — nativos e imigrantes digitais —, não deve, sequer, ser considerada.

Conquanto não seja absurda a classificação de Prensky em relação à influência das TDIC no modo de vida das pessoas, pode-se também divergir do autor quando defende que os nativos digitais naturalmente possuam maior facilidade de se apropriarem das TDIC. Afinal, muitas das principais tecnologias digitais que usamos hoje em dia foram criadas por sujeitos que, segundo as ideias de Prensky, deveriam ser classificadas como imigrantes digitais. Para citar alguns: Steve Jobs, Bill Gates e Tim Berners Lee. 
VII Congresso Brasileiro de Informática na Educação (CBIE 2018)

Anais do XXIV Workshop de Informática na Escola (WIE 2018)

Embora a classificação proposta por Prensky receba críticas, o fato é que a partir dela estabeleceram-se perfis, talvez estereotipados: alunos nativos digitais, que dominam TDIC, e professores imigrantes digitais, principiantes. Essa ideia, sobretudo na virada do milênio, parecia explicar pelo menos em parte as dificuldades vividas nas salas de aula. Explicitava um movimento necessário da parte dos professores para ingressarem na cultura digital. Logo, essa definição ganhou força. O tempo, porém, não pára.

Passaram-se mais de 40 anos desde que, procurando atender as demandas de um mundo em transformação, foram realizadas as primeiras experiências de uso educativo de TDIC em escolas brasileiras (Moraes, 1997). Em função da massificação das TDIC, nos dias atuais, não nascem mais "imigrantes digitais", salvo em alguns pontos remotos do planeta, onde não chegaram as TDIC, ou em grupos culturais muito fechados. Consequentemente, é inevitável que com o passar do tempo diminua a proporção deles em praticamente todos os segmentos da sociedade. Quanto aos nativos, na medida em que aumentam em número, é de se esperar que cada vez mais façam parte do processo de transformação cultural resultante da apropriação das TDIC.

Ao longo das últimas quatro décadas, uma nova geração passou pelas salas de aula de escolas e universidades e chegou ao mercado de trabalho. No setor empresarial uma parcela desses jovens está protagonizando inovações e algumas delas transformaram-se em projetos bilionários. Evidentemente, um contingente desses jovens está também na escola, todavia, não mais na posição de alunos. Com a passagem desses jovens pelos cursos de formação docente e com sua chegada às salas de aula, dúvidas surgem de imediato: esses professores estão provocando mudanças na sala de aula? Estão eles assumindo o protagonismo da tão decantada (re)volução da educação? Se há mudanças, por que elas não ocorrem na mesma velocidade e intensidade que acontecem em outros setores da sociedade?

Revisitando os conceitos de "nativos e imigrantes digitais", a proposta deste trabalho é discutir se a presença dos docentes nascidos a partir de 1980 — os quais, segundo Prensky seriam nativos digitais - está promovendo alterações significativas no que tange à inserção curricular das TDIC na escola. Pretende-se discutir estes aspectos tendo como base a importância da implementação dessas tecnologias no ambiente escolar, procurando não somente desconstruir estereótipos que não mais podem explicar o atual cenário na escola, mas também procurando aprofundar o olhar a fim de encontrar novos caminhos para problemas que persistem.

\section{A tecnologia digital na sala de aula}

A utilização das TDIC é uma realidade da nossa sociedade. Apesar disso, há uma dificuldade histórica de se alterar o "modus operandi" das salas de aula. Nos anos 1980, pesquisando a dificuldade de inclusão curricular do computador nas escolas americanas, Cuban (1986) identificou fatores que emperravam esse processo. Além da infraestrutura insuficiente e inadequada, do tempo insuficiente nas aulas, do excesso de conteúdo e do desinteresse de uma parte dos professores, Cuban concluiu que a frequência de uso educativo do computador era menor nas salas de aula cujo professor tivesse menor familiaridade com o dispositivo. No Brasil, nas décadas de 80/90, grande parte dos professores realizavam suas primeiras experiências com as TDIC. Nessa época, ministravam-se cursos de formação de educadores que tinham por objetivo apresentar as 
VII Congresso Brasileiro de Informática na Educação (CBIE 2018)

Anais do XXIV Workshop de Informática na Escola (WIE 2018)

tecnologias para o professor e demonstrar suas potencialidades. Segundo Valente (1999), mesmo com os diversos programas de formação, o professor ainda se sentia um principiante quando comparava seu domínio sobre as TDIC com aquele que seus alunos manifestavam.

Sem dúvida, não se pode prescindir da infraestrutura adequada para que as TDIC sejam adequadamente integradas ao currículo escolar. Porém, as TDIC, por si só, não promovem as mudanças desejadas. Valente (2008) aponta um exemplo frustrado de altos investimentos em computadores na escola: a implantação de programas que visavam colocar as TDIC nas salas de aula americanas em meados dos anos 80 . No Brasil, no ano de 2008, o Ministério da Educação, através do programa PROINFO, investiu na aquisição e implantação de aproximadamente 5.000 laboratórios de informática em escolas públicas. Os laboratórios, pelas dificuldades de manutenção e até logísticas não foram suficientes para integrar as TDIC ao currículo. Nos dias de hoje, as TDIC ainda são notadas no espaço da sala de aula muito mais como elemento que provoca a dispersão do estudante, do que como uma ferramenta com potencial transformador nos processos de ensino e aprendizagem. Tal é o caso dos smartphones: os alunos desejam utilizá-los, muitas vezes indiscriminadamente, e há escolas que criam estratégias para evitarem seu uso em seus domínios com a justificativa de evitar males como a dispersão e distração (Abreu, 2003; Moura, 2009; Sibilia, 2012). Nesse contexto, o que se vê é que na maioria das salas de aula, os dispositivos são empregados muito mais para dar um falso ar de inovação em velhas práticas. Para mudar esse quadro é fundamental que essas tecnologias sejam empregadas com sentido pedagógico que ultrapassa os limites do modelo educacional vigente. Nessa perspectiva, a figura do professor e seu papel na escolha e aplicação de determinada abordagem pedagógica merecem atenção.

Considerando o marco temporal estabelecido por Prensky, alguns dos alunos dos anos 1980/1990 assumiram, na atualidade, postos de professores. É de se esperar que eles, em função de suas particularidades, assim como fizeram enquanto alunos, não se conformassem com o modelo de ensino tradicional. Agora que ocupam a posição de professores, abrem-se perspectivas para que eles promovam mudanças na escola. Afinal, se trazem uma nova forma de pensar, determinada por uma nova configuração psicológica e talvez até apresentando modificações físicas, eles são diferentes, pensam, agem de maneira diferente e naturalmente incorporam as TDIC em seu cotidiano. Seria possível identificar sinais de que os professores nativos digitais estão atuando de modo diferente na sala de aula a ponto de se notar algo novo na escola brasileira?

\section{Repensando conceitos}

O presente trabalho tem como núcleo a discussão que surge como desdobramento de uma pesquisa com delineamento quali-quantitativo (Bogdan \& Biklen, 1994) realizada entre 2015 e 2017 por Nicolau (2017). Nessa pesquisa buscou-se compreender que razões justificavam discrepâncias nos perfis de usos particular e educativo das TDIC por professores de escolas da rede privada da região metropolitana da capital mineira. Um dos resultados dessa pesquisa causa um certo espanto ao leitor, motivando uma revisita aos termos nativo e imigrante digital. Além disso, sugere não somente um repensar da formação de professores, mas também a necessidade de revisão da postura da escola frente a necessidade de integração das TDIC no currículo. 
VII Congresso Brasileiro de Informática na Educação (CBIE 2018)

Anais do XXIV Workshop de Informática na Escola (WIE 2018)

Ao longo dos anos 2015 e 2017, a pesquisa se desenvolveu em três etapas. Na primeira delas participaram cento e quarenta e quatro professores da Educação Básica, representando aproximadamente um terço $(33,78 \%)$ do total de professores das três redes da educação privada investigadas. $\mathrm{O}$ instrumento de coleta de dados empregado nessa etapa foi o questionário online (QOL). Na segunda etapa, os dados foram analisados utilizando estatística descritiva, com testes qui-quadrado. Com base nas respostas, constituíram-se perfis de uso particular e educativo das TDIC. Na última etapa, foram realizadas entrevistas semi-estruturadas com 24 professores, e através de análise de conteúdo (Bardin, 1995), procurou-se identificar razões que justificassem as discrepâncias encontradas.

É oportuno destacar que todos os segmentos de ensino investigados possuem representatividade estatística na amostra de sujeitos: 45,83\% dos sujeitos lecionam no Ensino Fundamental I, um número um pouco maior $(50,00 \%)$ leciona no Ensino Fundamental II e o Ensino Médio conta um menor número de respondentes (32,64\%). Percebe-se que há professores que lecionam em mais de um segmento. O maior número de sujeitos do sexo feminino $(72,92 \%)$ corrobora a realidade histórica da Educação Básica brasileira, revelada pelo Instituto Nacional de Estudos e Pesquisas Educacionais Anísio Teixeira (2009).

Aproximadamente dois terços dos professores de cada segmento investigado têm menos de 40 anos, o que atesta os resultados do censo escolar realizado em 2013 pelo Instituto Nacional de Estudos e Pesquisas Educacionais Anísio Teixeira (2014) em escolas da rede privada. Todos os sujeitos têm idade inferior a 59 anos tendo sido agrupados em cinco faixas etárias: até 29 anos $(28,47 \%), 30$ a $39(38,19 \%), 40$ a 49 $(25,00 \%)$ e 50 a 59 anos $(8,33 \%)$.

As altas taxas de uso, sobretudo de uso particular de computador e celular, obtidas através da análise estatística das respostas do QOL (Tabela 1), mostram que o professor não deve mais ser considerado "principiante" no uso das TDIC, nem mesmo os professores de faixas etárias mais elevadas.

\begin{tabular}{|l|r|r|r|r|}
\cline { 2 - 5 } \multicolumn{1}{c|}{} & \multicolumn{2}{c|}{ Particular } & \multicolumn{2}{c|}{ Educativo } \\
\cline { 2 - 5 } \multicolumn{1}{c|}{} & Celular & Computador & Celular & Computador \\
\hline Até 29 anos & 95,12 & 97,56 & 21,95 & 58,54 \\
\hline Entre 30 e 39 anos & 98,18 & 94,55 & 47,27 & 83,64 \\
\hline Entre 40 e 49 anos & 88,89 & 94,44 & 36,11 & 75,00 \\
\hline Entre 50 e 59 anos & 100,00 & 91,67 & 50,00 & 91,67 \\
\hline
\end{tabular}

\section{Tabela 1: Proporção (\%) de uso frequente educativo e particular de TDIC por professores $(\mathrm{N}=144)$}

Costa, Ribeiro e Ferreira (2016) obtiveram resultados similares em relação às redes sociais: $90 \%$ dos professores utilizam o Facebook fora do ambiente escolar, enquanto que no ambiente escolar, apenas $30 \%$ deles faz uso educativo da tecnologia. O mesmo acontece em relação ao whatsapp, $100 \%$ fora e apenas $20 \%$ dentro da sala de aula (Costa, Ribeiro \& Ferreira, 2016). Estes dados mostram que a maior parte dos professores utilizam as TDIC em outros contextos, mas não no ambiente escolar. Na mesma direção apontam os resultados encontrados por Fantin e Rivoltella (2012): essas tecnologias não lhes são mais totalmente estranhas, entretanto, eles ainda apresentam 
VII Congresso Brasileiro de Informática na Educação (CBIE 2018)

Anais do XXIV Workshop de Informática na Escola (WIE 2018)

dificuldades em utilizá-las em atividades com os alunos, visto que as taxas de uso são significativamente menores no contexto de uso educativo.

Ao se investigar o percentual de uso frequente de smartphones e computadores em função da faixa etária do professor, utilizando o marco temporal proposto por Prensky (2001), verificou-se, com um certo espanto, que as faixas etárias abaixo de 40 anos apresentam proporções menores de uso educativo frequente de TDIC (Gráfico 1). Há uma inversão naquilo que se podia esperar de professores imigrantes e nativos digitais. Constata-se que, pelo menos nas salas de aula, a data de nascimento não é um aspecto determinante para o uso das tecnologias digitais.

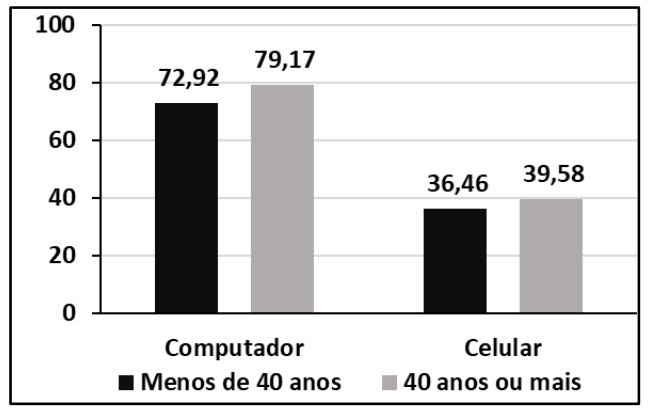

\section{Gráfico 1: Proporção (\%) de professores que fazem uso educativo frequente de Celular e Computador $(\mathrm{N}=144)$}

Ao se comparar os dados de uso frequente das TDIC nas faixas etárias "até 29 anos" e "Entre 50 e 59 anos" (Tabela 1), destaca-se ainda mais o contraste entre nativos e imigrantes: $21,95 \%$ contra $50,00 \%$ para uso educativo frequente celular e $91,67 \%$ contra 51,54\% para uso educativo frequente de computador. Esses resultados corroboram o pensamento de Kirschner e Bruyckere (2017) de que o conceito de nativo digital não se aplica de maneira satisfatória ao professor dentro do contexto escolar. Assim sendo, os conceitos de nativos e imigrantes digitais ficam em suspenso e surgem dúvidas. Por que os nascidos na Era Digital fora da escola avançam tanto na apropriação de uso das TDIC e dentro dela não? Agora que as TDIC não são mais estranhas ao professor é preciso reavaliar o cenário.

Para o uso efetivo das TDIC em sala de aula pode ser considerado determinante a formação para integração pedagógica dessas tecnologias. Cruz e Marinho (2012) indicam que os professores percebem a necessidade de inovar e desenvolver novas práticas pedagógicas que contemplem as TDIC, porém, percebe-se ao mesmo tempo, que os modos tradicionalmente organizados pela escola orientam a base da ação educativa da escola com o uso das TDIC. Este fato demonstra, argumentam os pesquisadores, que os objetivos pedagógicos do professor ainda se prendem muito aos livros didáticos e às práticas tradicionais de nossa escola. Freitas e Pinto (2015) corroboram esta percepção ao afirmar que, embora se percebam tímidos avanços na incorporação das TDIC, ainda é necessário avançar mais. A principal razão apontada para este quadro está na conduta do professor ao propor suas atividades, onde os autores percebem que há uma dificuldade dos docentes em vislumbrar o uso pedagógico das TDIC e, como consequência, eles continuam a empregar as formas tradicionais de ensino. Seria de se esperar esse comportamento por parte dos chamados imigrantes, mas por que os nativos digitais estão se conformando com essa situação? 
VII Congresso Brasileiro de Informática na Educação (CBIE 2018)

Anais do XXIV Workshop de Informática na Escola (WIE 2018)

O que percebemos é que há uma resistência à inovação no espaço escolar. Mesmo que os docentes sejam nativos digitais, e façam pleno uso das TDIC em suas vidas particulares, eles têm dificuldade de visualizar as possibilidades de uso educativo delas em seu espaço de trabalho (sala de aula). O que se nota é que há uma cultura escolar fortemente instituída que dificulta a percepção desses docentes para possibilidades de inovação pedagógica que envolvam a inserção das TDIC nas escolas.

Mizukami (1986) argumenta que há uma cultura escolar ligada de forma consistente a uma abordagem de ensino tradicional, onde ensinar é uma ação ligada à ideia de transmissão de conhecimentos, e aprender é reter o que foi ensinado. Nesse contexto, inserir as TDIC faz pouco sentido, ou gera uma inserção pobre. Recai sobre o professor, sobretudo dos chamados nativos digitais, a expectativa de que provoquem mudanças nessa cultura. Porém, conforme adverte Santos (1995, p.20), “o desempenho do professor é grandemente dependente de modelos de ensino internalizados ao longo de sua vida como estudante em contato estreito com professores.". Revela-se, então, uma das facetas mais perversas da trajetória formativa do docente. O professor, desde quando começou a frequentar aulas no Ensino Fundamental, passou a receber influência dessa cultura escolar, chegando até o ensino superior, onde estes aspectos são costumeiramente reforçados: vige o modelo educacional tradicional e praticamente não se oferece formação específica para uso educativo de TDIC (Gatti \& Barreto, 2009). Cabe ainda destacar que nesses cursos de formação inicial, os formadores também encontram dificuldades em modificar a sua prática docente.

Soma-se a esses problemas o pouco prestígio que as licenciaturas possuem na sociedade atual. Gatti (2000) denuncia que os alunos mais fracos procuram esses cursos devido a facilidade que apresentam. Sendo assim, os cursos de licenciatura apresentam defasagens significativas, o que também pode refletir no uso insuficiente das TDIC durante a formação. A consequência é que os futuros professores acabam não utilizando as tecnologias digitais na sala de aula (Texeira, el al., 2015). O exemplo é uma importante maneira de incentivar o uso das TDIC no ambiente escolar.

Como consequência, mesmo possuindo algum domínio sobre as TDIC, pois as utiliza em sua vida particular, o professor chega à sua sala de aula e perpetua as mesmas ideias e práticas, repetindo-as com seus alunos.

Em suma, diante do desafio de ruptura com padrões tradicionais, no que se refere ao uso educativo das TDIC, a formação do docente brasileiro que nasceu após os anos 1980 não é apenas insuficiente. Se considerarmos que esses professores nasceram imersos na cultura digital, utilizando as TDIC intensamente em seu cotidiano, sua trajetória escolar não forma para o uso das TDIC, pelo contrário, deforma-o.

E se ainda assim, esse profissional da educação resistir e planejar contornar barreiras que encontra na sala de aula para sincronizar suas atividades pedagógicas com a Era Digital, tais como, investimentos insuficientes, espaços inadequados $\mathrm{e}$ insuficiência de dispositivos, vai receber o golpe de misericórdia: o uso de tecnologias móveis, com apoio da legislação, é proibido na sala de aula. Trabalhando nesse ambiente de tensão constante criado pela proibição sumária que desagrada muitos de seus alunos, alguns, recém-chegados ao mercado de trabalho, declaram sentirem-se ameaçados quando cogitam de "flexibilizarem" as normas que a força da cultura escolar determina: 
VII Congresso Brasileiro de Informática na Educação (CBIE 2018)

Anais do XXIV Workshop de Informática na Escola (WIE 2018)

Kátia: [...] Mas eu acho que o medo que eu estou falando com você é o seguinte, um professor novo. Querendo ou não, todos nós profissionais somos cobrados, nós temos um nível de cobrança. [...] Quem vai falar para a escola sobre o seu trabalho? Aluno, porque ele que é fonte, o foco do seu trabalho. Então tem uma plaquinha ali "Proibido o uso de celular". Aí no final o aluno vai e fala assim: "Na aula do fulano todo mundo usa celular à vontade". A escola fala: “Como assim? mas não é proibido?". Então eu acho que muitos professores podem ter receio disso [...] Então, para o professor: "Não, a disciplina está controlada. Eu estou bem na fita". (Nicolau, 2017).

É curioso constatar que são os professores mais experientes, aqueles denominados imigrantes, os que se arriscam a burlar a legislação e as normas escolares para fazer algum uso educativo dos dispositivos móveis (Gráfico 1). Repetindo: a maior parte dos usos dos dispositivos móveis nas escolas pesquisadas, em função da proibição, ainda se dão, quando se dão, pela ação de professores imigrantes digitais. Persistindo essa situação, em mais algum tempo não teremos mais imigrantes digitais nas escolas. Porém, lamentavelmente, nesse momento poderão se extinguir as últimas iniciativas de sincronizar a escola com a sociedade da Era Digital. Considerando o papel que cabe à escola na formação das novas gerações para viverem como cibercidadãos, não fica uma lacuna na formação desses jovens? Que mensagens estamos transmitindo a eles quando proibimos sumariamente o uso educativo delas na escola? Serão eles incapazes de se controlar diante delas? Quando elas são proibidas na sala de aula não estamos dizendo aos jovens que tais tecnologias servem somente para o entretenimento?

\section{Algumas conclusões}

Atualmente, podemos dizer que ainda existem discrepâncias nos usos das TDIC no ambiente escolar e fora dele: os professores conhecem e reconhecem as tecnologias nos mais variados contextos, mas no ambiente escolar ainda não se explora todo seu potencial (Costa, Ribeiro \& Ferreira, 2016).

Um fator determinante para o quadro de pouco proveito do potencial educacional das TDIC é a cultura escolar. O que se constata é que os jovens professores, embora tenham nascido em um contexto de imersão nas tecnologias digitais e tenham domínio e a prática na operação dos recursos digitais, não as empregam nas atividade didáticas, pois não conseguem perceber a melhor forma de empregá-los frente a cultura escolar que está posta, onde inserir este tipo de recurso não altera muito a dinâmica das aulas. Na maioria das vezes eles conduzem as atividades de suas disciplinas da mesma forma que seus professores e que as normas escolares e legais permitem.

Em que pesem os riscos a que estão expostas crianças e jovens quando usam as TDIC, eles são reais, é urgente repensar a postura de proibição que vige. Afinal, antes das tecnologias digitais os alunos não estavam expostos a riscos na escola? Não seria mais adequado, então, que os educadores reconhecendo o potencial educacional das TDIC exigissem das autoridades competentes, por exemplo, a criação na Internet de espaços específicos para os mais jovens? A atitude de educar para o uso saudável, racional e ético da tecnologia, estabelecendo diálogo com os alunos, não é mais afeita ao espaço/tempo escolar do que a sumária proibição?

Neste contexto, uma alternativa possível seria repensar os cursos de formação de professores. A formação docente é uma condição indispensável e urgente para o melhor aproveitamento das TDIC enquanto ferramentas de ensino e aprendizagem. Deve-se ressaltar também que, mais relevante que o recurso empregado, é a forma como ele é 
VII Congresso Brasileiro de Informática na Educação (CBIE 2018)

Anais do XXIV Workshop de Informática na Escola (WIE 2018)

utilizado, e é aí que a formação docente se apresenta como importante estratégia para melhorar o ensino em todos os seus aspectos, independentemente se o docente é um nativo digital ou um imigrante digital. Frente a esse quadro, acreditamos que é preciso quebrar o ciclo pernicioso que deforma as novas gerações de professores, caso contrário, deixaremos de ter imigrantes e passaremos a formar e-migrantes digitais.

\section{Referências Bibliográficas}

Abreu, R. de A. dos S. (2003). A Internet na prática docente: novos desafios e conflitos para os educadores. 172 fls. Tese (Doutorado) - Pontifícia Universidade Católica do Rio de Janeiro. Departamento de Psicologia, Rio de Janeiro.

Bardin, L. (1995). Análise de Conteúdo. Lisboa: Edições 70.

Bogdan, R. \& Biklen, S. (1994) Investigação qualitativa em educação: uma introdução à teoria e aos métodos. Portugal, Porto Editora.

Castells, M. (1999). A Sociedade em rede. (6. ${ }^{\mathrm{a}}$ ed.). São Paulo: Paz e Terra.

Costa, F. J., Ribeiro, P. de C. \& Ferreira, J. R. (2016). A Distância das Tecnologias Digitais de Informação e Comunicação do Ambiente Escolar e a Formação de Professores. Formação docente. 8(2).

Cuban, L. (1986). Teachers and Machines: The Classroom Use of Technology Since 1920. New York: Teachers College Press.

Cruz, L. M. R. da \& Marinho, S. P. P. (2012) Internet e escola: práticas e representações de professores de uma escola UCA em Minas Gerais. In: XXII Simpósio Brasileiro de Informática na Educação, Anais... Workshop do Congresso Brasileiro de Informática na Educação. Recuperado de: http:// brie.org/pub/index.php/wcbie/article/download/1908/1845.

Fantin, M. \& Rivoltella, P. C. (2012). Cultura digital e formação de professores: usos da mídia, práticas culturais e desafios educativos. In: Fantin, M., Rivoltella, P. C.

(Orgs.). Cultura digital e escola: pesquisa e formação de professores, pp. 95-146, Campinas: Papirus.

Freitas, L. S. de \& Pinto, S. S. (2015). Discursos Coletivos que revelam a Inserção das Tecnologias da Informação e Comunicação no Ambiente Escolar. Prisma.com, 28, pp. 86-110.

Gatti, B. A. \& Barretto, E. S. de S. (2009). Professores do Brasil: impasses e desafios. Brasília: UNESCO. Recuperado de: $<$ http://unesdoc.unesco.org/images/0018/001846/184682por.pdf $>$.

Instituto Nacional de Estudos e Pesquisas Educacionais Anisio Teixeira. (2014). Censo escolar da educação básica 2013: resumo técnico. Brasília: INEP. Recuperado de: $<$ http://download.inep.gov.br/educacao_basica/censo_escolar/resumos_tecnicos/re sumo_tecnico_censo_educacao_basica_2013.pdf $>$.

Instituto Nacional de Estudos e Pesquisas Educacionais Anisio Teixeira. (2009). Estudo exploratório sobre o professor brasileiro: Com base nos resultados do Censo Escolar da Educação Básica 2007. Brasília. Recuperado de: <http://portal. mec.gov.br/dmdocuments/estudoprofessor.pdf $>$.

Lévy, P. (2011). Cibercultura. (3ª ed.). C. I. da Costa (Trad.). São Paulo: Ed. 34. 
VII Congresso Brasileiro de Informática na Educação (CBIE 2018)

Anais do XXIV Workshop de Informática na Escola (WIE 2018)

Kirschner, P. A., Bruyckere, P. de. (2017). The myths of the digital native and the multitasker. Teaching and Teacher Education, 67. pp. 135-142. Recuperado de: https://www.gwern.net/docs/psychology/2017-kirschner.pdf.

Marinho, S. P. P. (2006). Novas tecnologias e velhos currículos; já é hora de sincronizar. Recuperado de http://www.pucsp.br /ecurriculum.

Mizukami, M. da G. N. (1986). Ensino: as abordagens do processo. Editora Pedagógica e Universitária.

Moraes, M. C. (1997). Informática educativa no Brasil: uma história vivida,algumas lições aprendidas. Revista Brasileira de Informática na Educação, 1(1), abr. Recuperado de: http://brie.org/pub/index.php/rbie/article/viewFile/2320/2082.

Moura, A. (2009). Geração móvel: um ambiente de aprendizagem suportado por tecnologias móveis para a "geração polegar". In: CONFERÊNCIA INTERNACIONAL DE TIC NA EDUCAÇÃO, 6, Braga. Proceedings... Braga: Centro de Competência da Universidade do Minho, p. 49-77. Recuperado de: $<$ http://hdl.handle.net/1822/10056>.

Nicolaci-da-Costa, A. M. (2005). Primeiros contornos de uma nova "configuração psíquica". Caderno Cedes, Campinas, 25 (65), pp. 71-85, jan./abr. Recuperado de: http://www.scielo.br/pdf/ccedes/v25n65/a06v2565.pdf.

Nicolau R. M. (2017). Usos particular e educativo das tecnologias digitais de informação e comunicação pelo professor da educação básica na era digital: um estudo com base no modelo SAMR. (Dissertação de Mestrado). Belo Horizonte: Pontifícia Universidade Católica de MG, Programa de Pós-Graduação em Educação.

Prensky, M. (2001). Digital natives, digital immigrants. On the Horizon. 5 (9), out. Recuperado de: http://www.marcprensky.com/writing/Prensky\%20\%20Digital\%20Natives,\%20Digital\%20Immigrants\%20-\%20Part1.pdf.

Santos, L. L. (1995). Formação do professor e pedagogia crítica. In: FAZENDA, Ivani. A Pesquisa em Educação e as transformações do conhecimento. Campinas: Papirus, pp.17-41

Sibilia, P. (2012). Redes ou paredes: a escola em tempos de dispersão. Trad.Vera Ribeiro. Rio de Janeiro: Contraponto.

Texeira, Q. D. et al. (2015) Formação inicial de professores de Ciências e Biologia para tecnologia digital. In: Anais ... III Encontro Regional de Ensino de Biologia - Erebio, Juiz de Fora.

Valente, J. A. (Org.). (1999). O computador na sociedade do conhecimento. Campinas, SP: UNICAMP/NIED. Recuperado de: <http://nied.unicamp.br/oea/pub/livro1/>.

Valente, J. A. (2008). Visão analítica da informática na educação no Brasil: a questão da formação do professor. Recuperado de:

$<$ http://www.inf.ufsc.br/sbcie/revista/nr1/valente.htm>. 